\title{
Synthesis of Insecticides from Selected Plant Materials
}

\author{
*ASSIFUAH-HASFORD, KA; IMORO, ZA; COBBINA, JS \\ Department of Ecotourism and Environmental Management, University for Development Studies, Tamale, Ghana. Email: \\ assifuah.kojo@yahoo.com; Tel.: +233201412844
}

\begin{abstract}
The quest on sustainable development has called for eco-friendly anthropogenic activities. Consequently, this research work looked into the synthesis of biodegradable fumigants from plant materials. With simple technologies, formulations with insecticidal properties were produced from Neem seeds, Garlic bulbs, Orange peels and Penny royal leaves. The formulations were prepared with the following combinations; Neem oil + Garlic extract ('A'), Neem oil + Orange oil ('B'), Neem oil + Penny royal ('C'), Neem oil + Garlic extract + Orange oil + Penny royal ('D') and Garlic extract + Orange oil + Penny royal ('E'). Mosquitoes (Culex spp. and Anopheles spp.), houseflies (Musca domestica) and black ants (Lasius niger) were used as test specimens for the formulations prepared. Formulation 'A' yielded the best insecticidal property killing mosquitoes in an average time of $1.78 \pm 0.45$ seconds, houseflies in $5.18 \pm 0.43$ seconds and black ants in $23.52 \pm 0.54$ seconds. The rest of the formulations produced varying results. A non-uniform performance pattern was realized when further studies were conducted on the effects of dose and distance on the potency of the formulations. A comparative study between formulation 'A' and a chemical insecticide revealed that, formulation ' $A$ ' was more potent that the chemical insecticide in killing test specimens.
\end{abstract}

DOI: https://dx.doi.org/10.4314/jasem.v22i3.12

Copyright: Copyright () 2018 Assifuah-Hasford et al. This is an open access article distributed under the Creative Commons Attribution License (CCL), which permits unrestricted use, distribution, and reproduction in any medium, provided the original work is properly cited.

Dates: Received: 12 January 2018; Revised: 21 March: 2018; Accepted: 28 March 2018

Keywords: Insecticides, formulations, fumigants, mosquitoes, houseflies, black ants

Poor wastewater management contributes to the spread of vectors of diseases including mosquitoes. For instance, in Ghana about $38 \%$ of the population dispose of wastewater on streets, $21 \%$ in gutters, $35 \%$ in compounds and about $1 \%$ at undisclosed locations (Obuobie et al., 2006). Such poor wastewater handling practices provide fertile environments for mosquitoes and other vectors of diseases to thrive. This challenge actually cuts across all developing countries where the waste management sectors receive little budgetary allocations (WHO, 2008).

According to the World Health Organization, over one million people die annually from complications related to mosquito bites (WHO, 2013). To this end, several interventions have been put in place to arrest the situation. These include the distribution of mosquito sleeping nets, and the sale of mosquito coils and sprays. This has boosted the markets of these products but the challenge is, these interventions are mostly chemical based and thus calls for human and environmental concerns.

Mosquito fumigants must be regulated for human and environmental safety. In the USA, mosquito repellents must be registered by Environmental Protection Agency before they are marketed (USEPA, 2017). Consequently, the Centers for Disease Control and Prevention (CDC) recommend the use of products containing EPA-registered active ingredients (Mutebi, et al 2017). In Ghana too, the Food and Drugs Authority, Ghana Standards Authority and EPA have the mandate to regulate the importation, marketing and use of chemicals and chemical base products for the safety of all. The regulation of the use of chemical products is welcoming however chemicals still remain chemicals thus it's safer to look for less dangerous alternatives.

With the notion that, plant based mosquito fumigants and repellents are biodegradable, these products are gaining more use and/ recommendations. For instance, a number of field studies in India have highly rated neem-based preparations for killing mosquitoes (Maia and Moore, 2011). Neem oil has also proven to be an excellent larvicide against the mosquito genera Aedes, Anopheles and Culex (Murugan et al., 1996; Dua et al., 2009; Anjali et al., 2012; Benelli et al., 2015). In the Ghanaian local community, dried orange peels are burnt to ward off mosquitoes and flies. This insecticidal property of orange peels has scientifically been investigated and work by Anaso et al., (1990) showed that, orange peels can be used to fumigate mosquitoes. Also, Ezeonu et al., (2001) demonstrated that, Citrus sinensis (sweet orange) and Citrus aurantifolia (lime) had insecticidal activity against mosquitoes. In some 
rural settings in Northern Ghana, plants like pennyroyal are hung in front of doors, windows and in rooms to keep mosquitoes away. In this work, neem (Azadirachta indica) oil, sweet orange (Citrus sinensis) peels, pennyroyal (Mentha pulegium) leaves and garlic (Allium sativum) extract were used to prepare various formulations as fumigants.

\section{MATERIALS AND METHODS}

Preparation of extracts: Neem Oil: $8700 \mathrm{~g}$ of dried neem seeds were de-husked, milled and knead to smaller balls in an aluminum container. This was supplied with calculated amounts $(500 \mathrm{ml}-3500 \mathrm{ml})$ of hot water. The supply of hot water was repeated until maximum oil was obtained. Through decantation, oil was separated from water. Extracted oils were stored in sterilized, inert plastic bottles.

Orange Oil: Using the suggestion of Bloch (2011) orange oil was extracted using rubbing alcohol. Milled orange peels (354 g) were mixed with $1 \mathrm{~L}$ of warmed $\left(\sim 20{ }^{\circ} \mathrm{C}\right)$ alcohol. The mixture was shaken vigorous with a mechanical shaker for 15 minutes twice a day for a week. Resultant composite mixture was strained through a coffee filter, to remove milled peels and the filtrate placed in a wide glass container, covered with a paper towel and then placed in the open to facilitate the evaporation of the alcohol component. Extracted oil was collected and bottled.

Garlic extract: Carefully picked garlic balls (902 g) were blended into a puree for 10 minutes. With a strainer, garlic extract was obtained.

Pennyroyal extract: Just as with garlic, fresh pennyroyal leaves (362 g) were blended and strained through a strainer to obtain required volume of fluid. All extracts were stored in inert sterile bottles.

Formulations and their codes: Neem oil + garlic extract formulation - 'A', Neem oil + orange oil formulation - 'B', Neem oil + Pennyroyal extract formulation - 'C', Neem oil + garlic extract + orange oil + pennyroyal extract formulation- 'D', Garlic extract + orange oil + pennyroyal extract formulation - 'E'

Volumes of extracts used to prepare formulations: Considering the possible effects of dosage of extracts on the efficiency of formulations, two dose regimes were studied. That is high dose and low dose. Table 1 presents combinations and doses of formulations studied.

Table 1: Formulations and their respective doses

\begin{tabular}{lll}
\hline Formulation & Low volumes $(\mathbf{m l})$ & High volumes $(\mathbf{m l})$ \\
\hline 'A' & $10 \mathrm{ml} \mathrm{NO}+50 \mathrm{ml} \mathrm{GE}$ & $20 \mathrm{ml} \mathrm{NO}+60 \mathrm{ml} \mathrm{GE}$ \\
'B' & $10 \mathrm{ml} \mathrm{NO}+30 \mathrm{ml} \mathrm{OO}$ & $20 \mathrm{ml} \mathrm{NO}+40 \mathrm{ml} \mathrm{OO}$ \\
'C' & $10 \mathrm{ml} \mathrm{NO}+30 \mathrm{ml} \mathrm{PE}$ & $20 \mathrm{ml} \mathrm{NO}+40 \mathrm{ml} \mathrm{PE}$ \\
'D' & $10 \mathrm{mlNO}+50 \mathrm{ml} \mathrm{GE}+30 \mathrm{ml} \mathrm{OO}+30 \mathrm{ml}$ & $20 \mathrm{ml} \mathrm{NO}+60 \mathrm{ml} \mathrm{GE}+40 \mathrm{mlOO}+40 \mathrm{ml}$ \\
& $\mathrm{PE}$ & $\mathrm{PE}$ \\
'E' & $50 \mathrm{ml} \mathrm{GE}+30 \mathrm{ml} \mathrm{OO}+30 \mathrm{ml} \mathrm{PE}$ & $60 \mathrm{ml} \mathrm{GE}+40 \mathrm{ml} \mathrm{OO}+40 \mathrm{ml} \mathrm{PE}$ \\
\hline \multicolumn{2}{r}{ * Where; } & NO = Neem Oil; GE = Garlic Extract; PE = Pennyroyal Extract; OO = Orange Oil
\end{tabular}

Fumigation experiments: Test on mosquitoes (Culex spp. and Anopheles spp.): Experiments were carried out to test the efficacy of formulations prepared. Four fumigation regimes where studied in this exercise. That is; (a) low dose-formulations at a distance of $0.35 \mathrm{~m}$ range, (b) low dose-formulation at a distance of $1 \mathrm{~m}$ range, (c) high dose-formulation at a distance of $0.35 \mathrm{~m}$ range and (d) high dose-formulation at a distance of $1 \mathrm{~m}$ range. Mosquitoes were trapped in a $2 \mathrm{~m} \times 1 \mathrm{~m}$ netted cages. With the use of spray cans, this exercise was carried out successfully. On the average, about $30 \mathrm{ml}$ of each formulation was sprayed and the time taken to cause death recorded.

Test of formulations on houseflies (Musca domestica) and ants (Lasius niger): The formulations were also tried on houseflies and black ants to find out the possibility of using the formulations as general insecticides. Houseflies were caught with sweep nets from decaying organic matter (food) whiles black ants were sampled from ant holes. The formulations were sprayed on the houseflies and black ants and the time taken to cause death recorded. Both insects where sprayed with about $30 \mathrm{ml}$ each of formulations at $0.35 \mathrm{~m}$ range.

Efficiency of natural formulations against chemical formulations: This investigation was carried out to find out the performance of the best-synthesized plant based formulation against chemical competitor (name withheld) in killing mosquitoes. For this fumigation exercise, both products were sprayed at a short range of $0.35 \mathrm{~m}$.

\section{RESULTS AND DISCUSSION}

Though crude methods were used in the extraction and processing of formulations, quite interesting results were obtained in this study. 
Fumigation Experiment: All formulations prepared caused death to specimens' understudy but at varying times. This was expected because all the individual plant materials used in this study have been reported in literature to cause death to insects. However, in this work more focus was on mosquitoes since they have the greatest health and economic implications.

Tests of low doses of Formulations on mosquitoes at distances of 0.35 and $1 \mathrm{~m}$ : Considering the experiments conducted on low doses of formulations between the two distances understudy, formulation 'A' (Neem oil + Garlic extract) recorded the least average time (1.78 \pm 0.45 seconds) required to kill mosquitoes at $0.35 \mathrm{~m}$ (figure 1). This was followed by formulation ' $\mathrm{B}$ ' (1.89 \pm 0.35 seconds $)$ also at 0.35 $\mathrm{m}$ whiles formulation ' $\mathrm{D}$ ' (Neem Oil + Garlic extract + Orange oil + Penny royal extract) performed the least with an average time of $5.77 \pm 0.69$ seconds at 1 $\mathrm{m}$ range. The better performance of formulation ' $\mathrm{A}$ ' on test specimens was attributed to the garlic extract component in it. According to Bedford (2002), the powerful properties of garlic odour causes insects to be unable to build resistance to garlic treatments.

In the case of formulation ' $\mathrm{B}$ ' (Neem oil +Orange oil), its effectiveness was associated to the limonene content of orange oil. Limonene effectively suffocates insects by damaging their respiratory systems (Bloch, 2011). The poor performance of formulations with pennyroyal was possibly due to poor synergistic effects resulting from the formed compounds (in the presence of pennyroyal). That is either pennyroyal or compounds formed in the presence of pennyroyal was/were reducing the efficiency of the formulation.

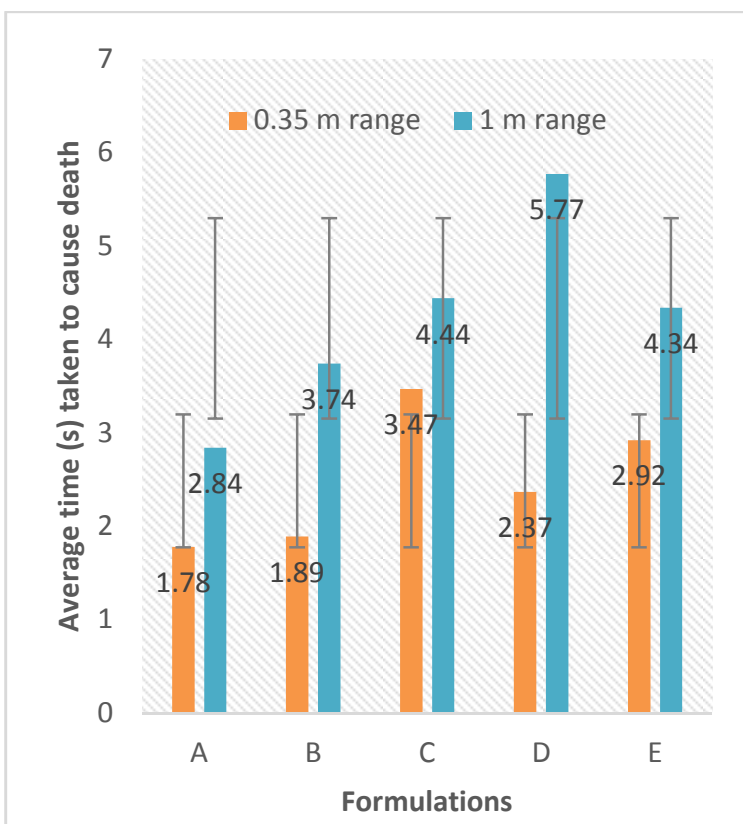

Fig 1. Average times taken to kill mosquitoes at low doses of formulations at distances of 0.35 and $1 \mathrm{~m}$

Data collected showed that an increase in distance increased the time required to kill mosquitoes (figure 1). Two sample t test showed statistical significant difference $(p=0.02)$ between the mean times recorded for the two distances studied $(0.35 \mathrm{~m}$ and 1 $\mathrm{m})$. The inference made from this observation was that, at close range more of the formulation reached the specimen than at long range $(1 \mathrm{~m})$. Since dose makes the poison, more dose implied more kills.

Tests of high doses of Formulations on mosquitoes at distances of 0.35 and $1 \mathrm{~m}$ : With regards to high doses of formulations, formulation ' $A$ ' again recorded the best performance with an average time of $2.48 \pm 0.73$ seconds at a distance of $0.35 \mathrm{~m}$ whiles formulation 'D' (Neem Oil + Garlic extract + Orange oil + Penny royal extract) as previously observed, recorded the least performance with an average time of $5.08 \pm$ 0.79 seconds at a distance of $0.35 \mathrm{~m}$ (figure 2). As explained earlier, formulation A's better performance was associated with the presence of garlic extract and formulation D's unsatisfactory performance attributed to its pennyroyal constituent. 


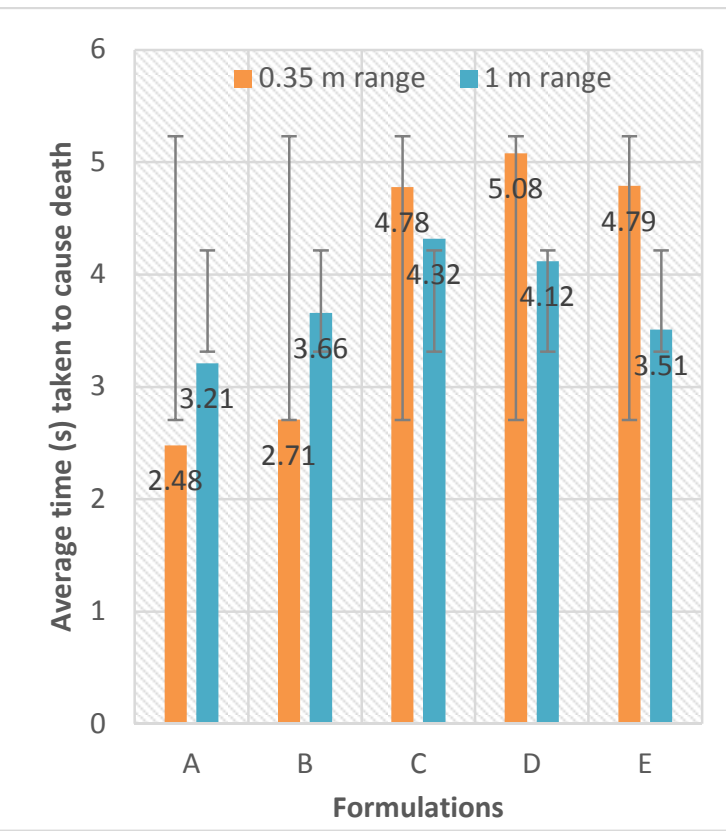

Fig 2. Average times taken to kill mosquitoes at high doses of formulations at distances of 0.35 and $1 \mathrm{~m}$

An increase in distances (from $0.35 \mathrm{~m}$ to $1 \mathrm{~m}$ ) did not necessarily result in an increase in time required to kill mosquitoes. This observation is shown in data points of formulations ' $C$ ', 'D' and 'E', (figure 2) where increment in distance did not correlate with times required to kill mosquitoes. Also, there was no statistical significant difference $(p=0.74)$ between the mean death times recorded between the distances investigated. This observation was associated to the possibility that, at high dose the concentrations of active ingredients in the formulations were probably optimal thus required the slightest contact on the right spot to cause death to mosquitoes. This also could account for why there was no statistical significant difference in the kill times between distances $0.35 \mathrm{~m}$ and $1 \mathrm{~m}$.

Comparison between the efficiency of low and high doses of formulations at a distance of $1 \mathrm{~m}$ : At a distance of $1 \mathrm{~m}$, high doses of formulations performed better than low doses except in the case of formulation 'A' (figure 3). The general better performances of high dose than low dose of formulations was attributed to the toxicological claim that, dose make the poison. This claim is backed by CDC (2015), which reports that, mosquito repellents with higher concentrations of active ingredient tend to be effective on mosquitoes than those with lower concentration.

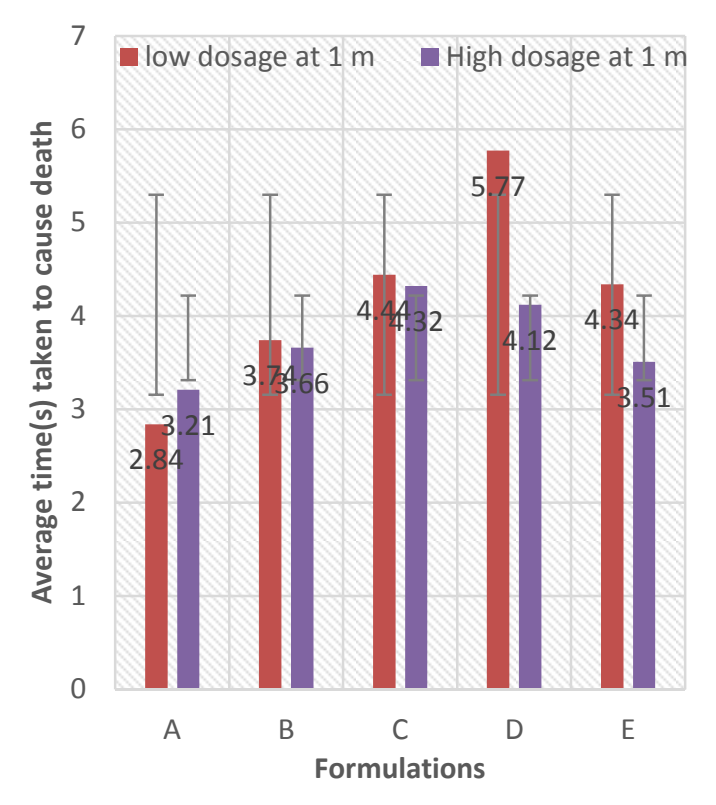

Fig 3. Average times (seconds) taken to kill mosquitoes by high and low dose of formulations at a distance of $1 \mathrm{~m}$

Comparison between the efficiency of low and high doses of formulations at a distance of $0.35 \mathrm{~m}$ : A rather interesting result was obtained when studying the effects of dose on mosquito kills at a distance of $0.35 \mathrm{~m}$. Low doses of each formulation did better than their corresponding high doses (figure 4). That is low doses killed faster than high doses. This was a special case we recommended that, some further investigations be done on.

Test on Houseflies (Musca domestica) and Black ants (Lasius niger): In this experiment too, formulation 'A' proved to be the most effective insecticide against houseflies and ants with the shortest killtimes of $5.18 \pm 0.33$ and $23.52 \pm 0.54$ seconds respectively (Table 2). Formulation ' $E$ ' took the longest time $(12.67 \pm 0.35 \mathrm{~s})$ to kill houseflies whiles formulation $\mathrm{C}$ took the longest time $(66.2 \pm 0.33 \mathrm{~s})$ to cause death to ants. The differences in the performance of formulations in this experiment was aligned with reasons stated about them in earlier sections. However, the marginal differences in 'kill times' between houseflies and ants could be due to the differences in their physiologies. 


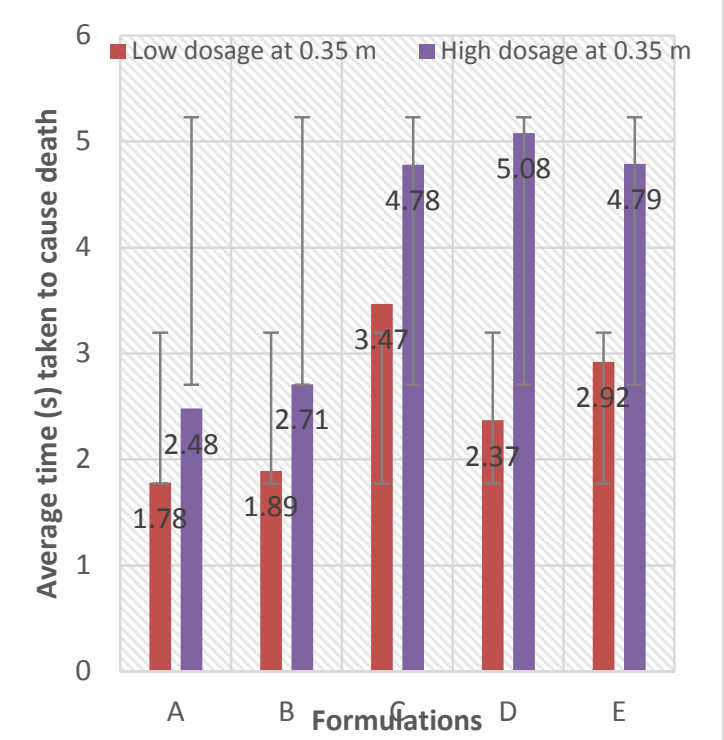

Fig 4. Average times (seconds) taken to kill mosquitoes by high and low doses of formulations at a distance of $0.35 \mathrm{~m}$

Table 2: Average times taken by formulations to kill houseflies and ants

\begin{tabular}{ccc}
\hline Formulations & \multicolumn{2}{c}{ Time taken to kill (seconds) } \\
\cline { 2 - 3 } 'A', & Houseflies & Ants \\
'B' & $11.22 \pm 0.33$ & $23.52 \pm 0.54$ \\
'C', & $8.83 \pm 0.27$ & $35.23 \pm 0.67$ \\
'D' & $10.90 \pm 0.44$ & $66.20 \pm 0.33$ \\
'E' & $12.67 \pm 0.35$ & $44.28 \pm 0.45$ \\
\hline
\end{tabular}

Comparison between formulation $A$ (Best formulation) and chemical insecticide: Formulation 'A' (Neem oil + Garlic extract) performed better than chemical insecticide when both were sprayed on test mosquitoes (Culex spp. And Anopheles spp.). Formulation 'A' took an average time of $2.40 \pm .0 .67$ seconds to kill mosquitoes whiles the chemical insecticide took an average time of $2.66 \pm 0.73$ seconds to cause death. This observation was attributed to the possibility that, formulation ' $\mathrm{A}$ ' contained more potent active ingredients which interacted fatally with mosquitoes better than its chemical competitor.

Conclusion: We hereby conclude that, the combinations of Neem oil + Garlic extracts and Neem oil + Orange oil in optimal concentrations presents insecticidal properties comparable to chemically synthesized insecticides. Thus this work further supports the fact that, plant materials are good substitutes for synthetic chemicals as insect fumigants.

Acknowledgement: We express our sincere gratitude to the management of Spanish Laboratory, UDS, Nyankpala campus for providing space and equipment for this research to be carried out. We however did not receive any direct funding for this work.

\section{REFERENCES}

Anaso, HU; Houno, LE; Onuora, D; Umerie, SC (1990). Potency of orange peel as a mosquito fumigant. Biol. Waste 34, 83-89.

Anjali, CH; Sharma, Y; Mukherjee, A; Chandrasekaran, N (2012). Neem oil (Azadirachta indica) nanoemulsion - a potent larvicidal agent against Culex quinquefasciatus. Pest Manag Sci. 68:158-163.

Bedford, H (2002). Garlic Successful as Natural Insect Repellent. SavaTree. Available online: http://www.savatree.com/garlic-insectrepellent.html (Accessed on 12 ${ }^{\text {th }}$ May, 2017).

Benelli, G; Murugan, K; Panneerselvam, C; Madhiyazhagan, P; Conti, B; Nicoletti, M (2015). Old ingredients for a new recipe? Neem cake, a low-cost botanical by-product in the fight against mosquito-borne diseases, Parasitol Res. 114:391-397.

Bloch, M (2011). Uses Available online: https://www.greenlivingtips.com/articles/orangepeel-tips.html (Accessed on 13th February, 2017) around the home for orange peel. Green living tips.

Centres for Disease Control and Prevention (CDC) (2015). Which mosquito repellents work best? CDC. Available online: https://www.cdc.gov/westnile/faq/repellent.html, (Accessed on 16th June, 2017).

Dua, VK; Pandey, AC; Raghavendra, K; Gupta, A; Sharma, T; Dash, A (2009). Larvicidal activity of neem oil (Azadirachta indica) formulation against mosquitoes. Malar J. 8:124.

Ezeonu, FC; Chidume, GI; Udedi, SC (2001). Insecticidal properties of volatile extracts of orange peels, Biores. Technol. 76, 273-274.

Maia, MF; Moore, SJ (2011). Plant-based insect repellents: a review of their efficacy, development and testing. Malar. J. 10(1), S11. Available online: https://www.ncbi.nlm.nih.gov/pmc/articles/PMC 3059459/ (Accessed on 30 ${ }^{\text {th }}$ March, 2017). 
Murugan, K; Babu, R; Jeyabalan, D; Senthil Kumar, N; Sivaramakrishnan, S (1996). Antipupational effect of neem oil and neem seed kernel extract against mosquito larvae of Anopheles stephensi (Liston). J Entomol Res. 20:137-139.

Mutebi, JP; Hawley, WA; Brogdon, WG (2017). Protection against Mosquitoes, Ticks, \& Other Arthropods, chapter 2, Centers for Disease Control and Prevention. Available online: https://wwwnc.cdc.gov/travel/yellowbook/2018/t he-pre-travel-consultation/protection-againstmosquitoes-ticks-other-arthropods (Accessed on 30th March, 2017).

Obuobie, E.; Keraita, B.; Danso, G.; Amoah, P.; Olu, F.; Coffie, O.; Raschid-Sally, L.; Drechel, P (2006). Irrigated Urban Vegetable Production in Ghana- Characteristics, Benefits and Risks. Available online: $w$ ww.ruaf.org/node/1046 (Accessed online: 30th February, 2017).
United States Environmental Protection Agency (USEPA) (2017). Regulation of Skin-Applied Repellents. USEPA.

World Health Organization (WHO) (2008). The Global Burden of Disease: 2004 update. Geneva: World Health Organization, p. 146. Available online:

http://www.who.int/healthinfo/global burden dis ease/2004 report update/en/ (Accessed on: 13th September, 2017).

World Health Organization (WHO) (2013). World Malaria Report 2013. WHO Library Cataloguing-in-Publication Data, pp. 282. Available online: www.who.int/malaria/publications/world ma laria report 2013/wmr2013 no profiles.pdf (Accessed on: 10th March, 2017). 